\title{
Usability and Utility Needs of Mobile Applications for Business Management among MSEs: A Case of Myshop in Uganda
}

\author{
Rehema Baguma $^{1}$, Marko Myllyluoma ${ }^{2}$, Nancy Mwakaba ${ }^{2}$, and Bridget Nakajubi ${ }^{3}$ \\ ${ }^{1}$ College of Computing \& Information Sciences, Makerere University \\ rbaguma@cit.mak.ac.ug \\ ${ }^{2}$ Nokia Research Centre Nairobi \\ \{marko.myllyluoma, ext-nancy.mwakaba\} @nokia.com \\ ${ }^{3}$ Grameen Applab-Uganda Office \\ bridget aapplab.org
}

\begin{abstract}
This paper discusses the usability needs of mobile applications for basic business management for Micro and Small Scale Enterprises (MSEs) in developing countries. This is based on results from a user study carried out in Uganda on 30 MSEs. The study was carried out on MyShop, an easy to use mobile business management application for cash transactions and book keeping designed for micro-entrepreneurs. The study investigated learning to use MyShop, the support MyShop gives to the user and its usefulness, and value addition to users. The study also covered the pleasure and stimulation MyShop gives to users. Results from the study show that MSE owners/shopkeepers would like an application that is easy to use such as have an intuitive navigation and a simple and clear language. They would also like an application that supports their unique context like multiple people operating a shop, selling goods on credit, ownership of multiple businesses, use of low end phones and regular load shedding. In terms of value addition, MSEs would like the application to assist them in managing the daily operations and developing the business in the long term such as marketing, time saving and control over business.
\end{abstract}

Keywords: Usability, mobile applications, utility, MSEs, MyShop, business management.

\section{Introduction}

Micro and Small Scale Enterprises (MSEs) play important roles in the economic growth and sustainable development of every nation (Moore et al., 2008). The development and growth of MSEs can provide solutions to the problem of high unemployment facing many countries especially developing countries. Maseko and Manyani (2012) noted that MSEs have low start-up costs, low risk and can exploit untapped knowledge bases of creativity in the population for new product development. According to East African Community (EAC) (2010), MSEs are often considered a key source of productivity, growth and job creation. They promote equitable 
distribution of income because they are owned by relatively low income entrepreneurs, most of whom are women. MSEs are therefore important instruments for both income distribution and equitable participation in the process of economic development. For governments, well-managed and healthy MSEs are a source of revenue in form of taxes. Uganda has 0.8 million MSEs that contribute $20 \%$ to GDP and employ over 1.5 million people (EAC, 2010). In Uganda, MSEs are categorized according to number of employees, value of capital investments and turn over as follows:

Table 1. MSE Definition used in Uganda

\begin{tabular}{|l|l|l|l|}
\hline & $\begin{array}{l}\text { Number of Em- } \\
\text { ployees (Max) }\end{array}$ & $\begin{array}{l}\text { Capital Investments (Max } \\
\text { in UGX) }\end{array}$ & Revenue (Max in UGX) \\
\hline Micro & 4 & $12 \mathrm{~m}$ (USD 4800) & $12 \mathrm{~m}$ (USD 4800) \\
\hline Small & 50 & $360 \mathrm{~m}$ (USD 144000) & $360 \mathrm{~m}$ (USD 4800) \\
\hline
\end{tabular}

From EAC (2010)

As mobile phones are multiplying in the developing world, many social economic services and applications are being innovated by Mobile Network Operators (MNOs), not for profit and for profit organizations. Hellstrom (2010) noted that in a region where the vast majority have limited resources among other constraints, mobile phone solutions provide a means of extending a number of services to the poor who are in rural and remote areas. However, Corbett (2008) remarked that as sales, access, and coverage continue to grow, it is yet to be seen whether the mobile phone technology will play a significant, sustained role in alleviating poverty in the developing world. In most developing countries such as Uganda, while operators' focus has been people with a high disposable income and revenue generating services like urban youth and entertainment, services and development oriented applications have not been prioritised. Therefore the number of relevant applications for economic and social development is still limited.

On the other hand, efforts to develop mobile applications for banking and managing business internationally have been focused on applications for high end phones such as iPhone (e.g. Mint and Splash Money), Android (Xero) and ipad (quickbooks mobile). These sophiscated mobile applications are out of reach for MSEs in developing countries due to their high cost, hi-tech nature (most MSE owners are computer illiterate), energy efficiency (battery consumption) and data dependency (online connection). As a result there is need for applications that can run on low end phones that most MSEs in developing countries use. In addition, most available applications are mainly about personal financial activities such as banking than managing business activities of a business. For example iPhones's Ledger Docs is used for digital capturing of ledger receipts. Mint, another iPhone application, updates account balances, transmits real-time alerts to the phone for low account balances, over-budget, and tracks strange buying and selling activity. Android's Xero keeps the user updated about business finances and cashflow, creates real time reports as well as integrated invoicing for precision management.

To-date, most research on MSEs and mobile phone usage has been focused on the communication function of the phone and mobile commerce. Examples of such include; Kwaka (2012) who reports about mobile phone usage by MSEs in semi-rural 
Ghana; Melchioly and Aebø (2010) reports about added value concerning economic growth and entrepreneurship to SMEs in terms of communication with suppliers and customers, market solicitation, social cohesion and operational cost reduction; Esselaar et al (2008) reports on ICT usage and its impact on profitability of SMEs in 13 African Countries. Others are Escobari and Donner (2009), Matambalya and Sussana (2012), Dorflinger et al (2009), Edim and Muyingi (2010) and Giridher et al (2009).

Hence little so far has been done about using mobile phones for business management. Palsey (2011) reports about a mobile book keeping application developed as part of her Honours studies to enable MSEs keep records of their business transactions and automatically generate financial reports. However, the application in question is not available in the public domain. Therefore it is not clear whether it went beyond the university laboratory to be used by the target users.

Business management for MSEs like other business types is important for planning, budgeting and forecasting, taxation, access to finance among other functions. EAC (2010) noted that the quality of information that a firm produces and maintains determines its access to finance. However, EAC (2010) found out that majority of Micro and Small Scale Enterprises do not keep proper records due to lack of appropriate skills. Therefore efforts to provide simple business management tools tailored to the needs and characteristics of MSEs are greatly needed.

This paper discusses attributes for an easy to use and beneficial (utility) mobile application for business management among MSEs in developing countries. This is based on results of a user study carried out in Uganda on MyShop. MyShop is mobile business application for cash transactions and book keeping designed for microentrepreneurs. The study covered ease of use and utility evaluation of MyShop. It investigated learning to use MyShop and the phone (Nokia c3-01), support MyShop gives to the user, the pleasure and stimulation MyShop gives to users and the usefulness, and value addition of MyShop to users.

Nielsen (2012) refers to usability as a quality attribute that assesses how easy the user interfaces are to use. According to Schumacher and Lowry (2010), usability is the effectiveness, efficiency and satisfaction with which specified users can achieve specified goals in a particular environment. Utility on the other hand refers to the design's functionality i.e. whether a product or service does what users need (Nielsen, 2012). Ease of use and utility are equally important and together determine whether something is useful. Nielsen (2012) noted that it matters little that something is easy to use if it is not what you want and it is also no good if the system can hypothetically do what you want, but you cannot make it happen because the user interface is too difficult. Therefore the attributes discussed in this work are concerned with ease of use and utility needs of mobile applications for business management among MSEs. In particular, this is discussed in the perspective of the MyShop application.

\section{$2 \quad$ Methodology}

The ease of use and utility evaluation of MyShop was carried out on a sample of 30 MSEs dealing in products and services in and around Kampala city, Uganda. The study was conducted between November 2011 to March 2012. The study areas included one urban location and three peri-urban areas namely: Kampala city centre, Kawempe trading centre, Kyaliwajjala trading centre and Natete trading centre. 
The rationale for selecting one urban location versus 3 peri-urban ones was because most MSEs in Uganda operate in peri-urban and rural areas.

The 30 participants were chosen purposively based on the following attributes:

ability to read and write in English. The minimum requirement was completion of Ordinary Level (Middle School) but completion of Advanced Level (High School) was preferred. This attribute was important because the application was in English. The second requirement was ability to use Short Message Service (SMS) or mobile money service. This gave an indication of experience with data applications. In addition, some individual user characteristics were preferred in order to be sure that the participant would perform and fulfill all expected tasks. These included: able to attend trainings, willingness to use the application in day to day business, willingness to commit at least 1 hour daily to update information and commitment to meet data collection requirements. Other desired attributes included: located 10 - $15 \mathrm{kms}$ from central Kampala, small scale dealing in products and services, 1+ years of operation; $10+$ transactions/day, owner operated or employing not more than 5 people and between 200 and 2000 USD start up capital.

Three weeks to the beginning of the study, participants were trained (half day) in using the application and phone. After the training, they were given phones loaded with the application to use for three weeks before beginning of interviews. In addition, they were given a user guide covering using the main menu and application settings, and a summary of how each of the application's functions work.

The study was conducted through weekly field visits to the study sites during which, the study team observed how participants were using the application in their cash and book keeping activities. In addition, 3 questionnaires on ease of use, reliability and enjoyment, and utility were administered to participants to elicit quantitative and more detailed qualitative data. There was no requirement for approval from an Institutional Review Board before running the study.

\section{Discussion of Findings}

\subsection{About MSEs That Participated}

The study covered one urban area and three peri-urban areas around Kampala city. The study population was 30 MSEs dealing in products and services. Of the 30 participants, $53 \%$ were male and $47 \%$ female. Fifty percent had a degree or diploma, 33\% had completed Advanced Level (High School) while 17\% had completed Ordinary Level (Middle School). All the participants could read and write in English and could use SMS or mobile money. The business premises were located 10-15 KMs from central Kampala and $83 \%$ had been in operation for $1+$ years. All participating businesses had $10+$ transactions/day, were owner operated or employing not more than 5 people and $59 \%$ of the businesses were worth 10 million Uganda Shillings and above (approximately $\$ 4,200$ USD). In the findings discussed below, the names given are not actual names of participants for purposes of protecting the identity and businesses of participants. 


\subsection{Usability and Utility Needs of Mobile Applications for Business Management among MSEs: A Case of Myshop in Uganda}

This section discusses ease of use and utility needs of mobile applications for business management among MSEs in developing countries. This is based on results from a user evaluation study of MyShop. MyShop was developed by Nokia and has four main functionalities: selling stock (called "Sell"), recording sales and expenses (called "Records"), purchases and inventory management (called "Stock"), and monitoring of business performance over time (called "Reports"). It is available for free in Nokia's online store on http://store.ovi.com/content/249179.

The needs discussed are categorized into: ease of use, support to the user, usefulness and value addition to MSE owners/shopkeepers and the pleasure, and stimulation to the user. According to the Webster online dictionary, ease of use is the property of a product or thing that a user can operate without having to overcome a steep learning curve. High ease of use makes products or systems intuitive to use to the average user. In the context of computer/mobile applications, ease of use simply means an application that is effortless to understand, find what is needed and do what one wants to do. In addition, the user's context such as characteristics of the environment, language preference, cultural or community practices, unique business characteristics, etc., need to be understood and supported for better usability. These attributes are categorized as support to the user in this work. Further more, for a product, service or system to be useful, it should be both easy to use and of value to the users (Nielsen, 2012). Hence value attributes are also important and are classified as value to the users in this work. Besides ease of use, supporting users' context and being of value, a product, service or system should be pleasing and motivating to users to succeed.

\subsubsection{Ease of Use}

This subsection discusses attributes that can make mobile applications for business management effortless to use for MSE owners/shopkeepers. These include:

Using the application as transactions happen: MSE owners/shopkeepers prefer to use the application as transactions happen. In the MyShop usability evaluation study, $80 \%$ of the shopkeepers interviewed preferred to use the application as transactions happen. They noted that this helps them avoid forgetting details of transactions performed as Mariam, a shopkeeper from Kyaliwajjala trading centre remarked: "I use it as I transact my business throughout the day because I need to ensure that all records have been entered". In line with this need, developers of mobile applications for business management among MSEs need to focus on making it easier and faster to record transactions because efficiency is very important to shopkeepers.

Auto Computation of Tasks Such as Profits and Losses: MSE owners like the auto computation of tasks by computer/mobile applications. This is much easier and less error prone compared to manual computations on paper. Jolly a shopkeeper in Kawempe trading centre equipped: "auto calculation of sales, profits and losses makes my life easy".

Intuitive Navigation: MSE owners want a well organized interface that they can easily navigate and find functions needed. Participants in the MyShop study found it easy to use the simple navigation structure of MyShop (4 items at the first level and 
3-6 items inside each of the screens on the second level). Betty a saloon operator in Kawempe trading centre said: "I like the fact that it is easy to navigate through the application and know where to find what function when I need it".

Simple and clear language: MSE owners/shopkeepers would like mobile applications written in simple and clear business management language. This is preferred because most of them have low levels of education and do not have formal training in book keeping. In the MyShop study, 68\% strongly agreed that the language used in MyShop is clear and simple which made the application easy to use. Violet, a drug shop attendant in Kawempe trading centre noted: "the application uses simple business language and the English is clear".

Representative icons: Using icons that are a clear representation of intended function makes such applications easy to use for MSEs. In the MyShop study, most participants found the icons used meaningful in relation to the intended function. Jumba, an operator of a crafts shop in Kyaliwajjala trading centre said: "the icons explain well what function they represent e.g. using a symbol of money notes to mean sell clearly shows that whatever is under that function is money coming in". A key thing about the understandability of the icons is that they are not global abstract metaphors but tangible everyday items. For example, instead of a shopping cart, there is a basket and for stock, the initial metaphor of a delivery truck, was replaced with a pile of boxes.

Easy to learn: MSEs find applications that are easy to learn easy to use. In the MyShop research study, 24\% strongly agreed and 48\% agreed that learning MyShop was easy which made use of the application easy. This was attributed to the ease of finding functions, simple and clear language, representative icons and an easy to operate phone.

\subsubsection{Support to the User}

This subsection discusses usability attributes that address contextual needs of MSEs from mobile applications for business management. These include;

Multiple user accounts: Some MSE owners have employees hence it is important for the mobile application to support multiple user accounts with varying privileges. This will enable shop owners/managers to restrict access to information on certain aspects such as reports. In the MyShop study, $80 \%$ of the participants preferred using the application alone (which meant running a parallel manual system) because the version used did not support multiple user accounts.

Portability: MSEs prefer the mobile application to a computer application due to its portability. This helps them carry out offsite business management activities like restocking more easily. In the MyShop study, 35\% strongly agreed and 57\% agreed that they enjoy using MyShop in business partly due to its portability. Agnes, a grocery shop attendant in Kampala city centre noted: "I go with it when shopping for new stock and I use it to remind me about restocking needs".

Easy to operate phone: The phone(s) on which the application works must be easy to operate. In the MyShop study, 28\% strongly agreed and $40 \%$ agreed that the phone on which MyShop was loaded, was easy to use. This was attributed to the semi-touch screen phone (small touch screen and large physical keys) and participants' previous experience with other Nokia models. Isaac, a video library operator in Kawempe 
trading centre noted that: "It is very easy to find functions with the touch screen". This finding is not isolated because White (2010) noted that less educated and less technology savy mobile phone users find touch screens easier to use because they directly manipulate interface objects rather than using third party interaction aids like a mouse and keyboard.

Short introduction to bookkeeping: EAC (2010) in a study about MSEs in E. African countries found that majority of micro and small enterprises do not keep proper records due to lack of appropriate skills. In the MyShop study, the "Reports" module was used less because most participants confused the "Records" module to offer similar functions to "Reports" and or did not understand how it works. For example Christine, a beverages shop operator in Kyaliwajjala trading centre said: "I really did not understand how the reports function works and since I can assess the business performance with records then I do not need to use reports". The user manual in the version of MyShop used did not cover book keeping. Including an introduction to book keeping in the help module, can benefit those new to book keeping concepts.

Provide cloud or local backup storage: To prevent against data loss in case of loss of the phone or a problem with the hardware or software, it is important to provide for data back up locally or in the cloud. The MyShop version that was used in the study did not have this provision.

Device independence: It is important to make such applications compatible with low end phones so that users are not limited on device choice. In the study, the Nokia c301 used had a short battery life (which was a problem to participants due to regular load shedding). In addition, Nokia c3-01 costs approximately USD 200 hence is expensive for most MSE owners but the current version of MyShop runs on lower end Nokia devices that cost as low as USD 50.

Provide for selling services: The MSE sector has both product and service businesses with varying operational procedures. Therefore it is important for such applications to provide for both. One way is to have a product and service version with services offered and details of offering in the place of stock. The MyShop version used was only applicable to MSEs dealing in physical products such as retail shops. Therefore it was a challenge using it on businesses dealing in services like video libraries.

Provide for credit transactions: Selling on credit is a common practice especially for retail shops in Uganda and other African countries. The MyShop version used in the study did not have this provision and participants expressed a need for it. Betty, a cosmetics shop operator in Kawempe trading centre said: "It is very difficult to keep track of items sold on credit, yet we sometimes offer goods to on credit".

Local language version: Most MSE owners are not comfortable with English due to low levels of education. UNESCO (2007) reported that one of the challenges of delivering mobile phone based services is that $41 \%$ of the population in developing countries is non-literate and even the literate among the poor are typically novice users of computer technologies. Due to this limitation, the study purposively selected participants whose level of education ranged from Ordinary Level (Middle School) and above. Therefore for this application to succeed in the market like Uganda there is need for it to have a version in a language. In the study, participants requested for a version in Luganda, the most dominant local language in Uganda. 
Use one install for two or more businesses: Multiple business ownership is common among business people in Uganda and Africa. Ronald, a video library operator in Natete trading centre said: "I have a video library and a phone accessories shop hence I would prefer being able to use one copy of MyShop for both businesses". Therefore it is important to make it possible for one install to be used for two or more businesses for example through a multi business edition.

Link application to mobile money: Like other business people, MSEs make a lot of financial transactions such as paying suppliers, utilities, employees, receiving payments from customers, etc. However, the banking infrastructure in Uganda like other developing countries is still severely limited and very few people can meet requirements of banking institutions (FinScope, 2007). Participants in the study revealed that some of the payments they make in their businesses such as paying suppliers, rent, and receiving payment from some customers are settled using mobile money. Therefore such a function would make the application more useful and relevant for MSEs.

\subsubsection{Usefulness and Value addition to MSE Owners/Shopkeepers}

This subsection discusses attributes that address relevancy and value addition attributes MSEs desire from mobile applications for business management.

Marketing function: MSEs would like an application that can on top of basic book keeping, perform related functions such as marketing. This can be achieved through mass dissemination of marketing information via Short Message Service (SMS) or multimedia messaging. During the study, some participants used the phone camera to take pictures of their stock for marketing to potential customers. Moses, an operator of an arts and crafts shop in Kyaliwajjala trading centre noted: "I take pictures of current stock and sold out items to show to potential customers".

Reduction of workload: MSEs would like an application that reduces their work load thereby making work easier. $60 \%$ of the study participants agreed that using MyShop had made work easier in their business such as in stock taking and tracking profits and losses. Deborah, a supermarket operator in Kyaliwajjala remarked: "I track the stock automatically within the application which less tiresome".

Time saving: MSEs desire applications that help them save time in the management of their businesses creating more efficiency. In the study, over $60 \%$ agreed that MyShop saves time in business management because of automated functions. Joshua an airtime supplier from city centre remarked that: "MyShop has promoted efficiency in business information recording/book keeping”.

Safe keeping of business information: MSEs would like an application that keeps their business information safe and secure. Katende, a shopkeeper in Kawempe trading centre remarked: "My business is individual therefore I like it that MyShop keeps my business information away from third parties". Therefore it is important for such applications to restrict access to some information like reports.

Control over business: MSEs would like the mobile application to help them better control their business such as keeping track when away and easy assessment of performance. Jackson, a mobile video and disco operator in Natete trading centre noted: "the business' performance is easily assessed since everything is automated". This can be further enhanced by making the app an online service that syncs across multiple shopkeepers so that the business owner can monitor while away. 


\subsubsection{Pleasure and Stimulation to the User}

This subsection discusses attributes that will make mobile applications for business management pleasing and motivating to use for MSE owners/shopkeepers.

Exciting experience: MSE would be attracted to an application that gives them an exciting experience. This can be achieved through adaptation of the application to their business needs. In the MyShop usability study, $17 \%$ had an extremely exciting experience while $62 \%$ had an exciting experience. This was attributed to relevancy of MyShop and the semi-touch screen phone which most of them were using for the first time. Miriam a shopkeeper in Kyaliwajjala trading centre said: "MyShop helps me make business decisions based on facts e.g. every day, I look at MyShop to find out what needs restocking before I restock".

Enjoy using the application: MSEs would like an application that they enjoy using. To achieve this, the application must be relevant to their needs and context. In the MyShop study, 35\% strongly agreed and 57\% agreed that they enjoy using MyShop in business due to its portability and auto computation of tasks. Doris, a mini supermarket operator in Kyaliwajjala said: "I go with it when shopping for new stock and I use it to remind me about restocking needs".

\section{Conclusion}

The potential value of Mobile applications for business management among MSEs is enormous but for this to be realized such applications must be usable and have high utility to the target MSEs. For MSEs in developing countries such as Uganda, such applications must be effortless to use, relevant to the needs and context of MSEs add value to their businesses and be pleasurable and stimulating to use. Future efforts on such applications should focus on usability and utility for the target market segments.

Acknowledgements. We extend our sincere thanks to Nokia that allowed us to use results from an originally non-academic usability evaluation study on MyShop in Uganda. We also extend thanks to Grammeen Applab-Uganda Office in particular Sean Paavo Krepp, the Country Director and Annete Bogere, the Content and Services Manager. Grammen-Applab coordinated the study in Uganda as a local partner on behalf of Nokia. Our since thanks also go to Gabriel White who worked as a User Experience Consultant and Richard Nuwagaba, and Andrew Gagwera who worked as Research Assistants on the study.

\section{References}

1. Donner, J., Escobari, M. (no date). A review of the research on mobile use by micro and small enterprises (MSEs) ICTD 2009, Qatar, April 17-19 (2009)

2. Dorflinger, J., et al.: Mobile Commerce in Rural South Africa-Proof of Concept of Mobile Solutions for the Next Billion Mobile Consumers. In: Proc. WOWMOM 2009 (2009)

3. Dim, A.E., Muyingi, H., N., A.: Mobile Commerce Application for Rural Economy Development: A case study for Dwesa. In: Proc. SAICSIT 2010. ACM Press (2010) 
4. Esselaar, S., Stork, C., Ndiwalana, A., Een-Swarray, M.: ICT Usage and Its Impact on Profitability of SMEs in 13 African Countries (2008)

5. Faris, S.: Bookkeeping Made Easy...And Mobile With The Help Of Some Great New Apps. (2012),

http: / /www.smallbiztechnology.com/archive/2012/03/

bookkeeping-made-easy-and-mobile-with-the-help-of-somegreat-new-apps.html / (retrieved on June 13, 2012)

6. Gilbert, C.: Usability Evaluation. In: Soegaard, M., Dam, R.F. (eds.) Encyclopedia of Human-Computer Interaction. The Interaction Design Foundation, Aarhus (2012),

http: / /www. interaction-design.org/encyclopedia/

usability_evaluation.html

7. Giridher, T., et al.: Mobile Applications for Informal Economies. In: Proc. IMCSIT 2009. IEEE (2009)

8. Hellström, J.: The Innovative Use of Mobile Applications in East Africa, Sida Review 2010, vol. 12. Edita (2010)

9. Kwakwa, A.P.: Mobile Phone Usage by Micro and Small Scale Enterprises in Semi-Rural Ghana. International Review of Management and Marketing Journal 2(3) (2012)

10. Melchioly, R.S., Sæbø, Ø.: ICTs and Development: Nature of Mobile Phones usage for SMEs Economic Development - An Exploratory Study in Morogoro, Tanzania. Technical Commission 9 - Relationship between Computers and Society, March 22-23. IFIP, vol. 201, Workshop at Makerere University, Uganda (2010)

11. Maseko, N., Manyani, O.: Accounting practices of SMEs in Zimbabwe: An investigative study of record keeping for performance measurement (A case study of Bindura). Journal of Accounting and Taxation 3(8), 171-181 (2012)

12. Moore, et al.: Managing small business: An entrepreneurial emphasis, 14th edn. (2008)

13. Nielsen, J.: Usability 101: Introduction to Usability (2012), http://www. useit.com/alertbox/20030825.html

(retrieved on October 1, 2012)

14. Schumacher, R.M., Lowry, S.Z.: NIST Guide to the Processes Approach for Improving the Usability of Electronic Health Records. National Institute of Standards and Technology (2010)

15. SMEs get productivity from mobile applications,

http: / / www. computerweekly.com/news / 2240088236 /

SMEs-get-productivity-from-mobile-applications

(retrieved on September 25)

16. The East African Community (EAC), Study on the Promotion of Micro, Small and Medium Enterprises (MSMEs) in the East African Region, consolidated report by Ernst and Young. (2010), http: / / www . ugandainvest. go.ug (retrieved on June 30)

17. UNESCO. UNESCO Institute of Statistics Data Centre, regional literacy rates (2007), http://stats.uis.unesco.org/unesco/TableViewer/tableView.asp $\mathrm{x}$ ?ReportId=y201 (retrieved on June 12, 2012)

18. Wamuyu, E., Maharaj: Usage of mobile technologies in Kenya. The African Journal of Information Systems (2011)

19. Webster Online Dictionary, http://www. websters-online-dictionary.org (retrieved on October 2, 2012)

20. White, G.: Designing Mobile services for the Non-literate communities. In: The Proceedings of the 2nd International Conference on M4D 2010, Kampala, Uganda (2010)

21. Xero Accounting Software, http://www.getapp.com/xero-application (retrieved on September 20) 